\title{
Pregnancy loss, infant death, and suffering: legacy of syphilis and gonorrhoea in Africa
}

\author{
K F SCHULZ, W CATES JR, P R O'MARA \\ From the US Department of Health and Human Services, Public Health Service, Centers for Disease Control, \\ Center for Prevention Services, Division of Sexually Transmitted Diseases, Atlanta, Georgia, USA
}

SUMMARY Africa in the 1980s appears to be facing problems associated with syphilis and gonorrhoea during pregnancy similar in severity and magnitude to those faced by the western world in the early 1900s. From a review of published reports, the prevalence of syphilis seroreactivity in pregnant women in many parts of Africa is at least $10 \%$. Assuming this level of seroreactivity, we estimate that $5 \%$ to $8 \%$ of all pregnancies surviving past 12 weeks will have an adverse outcome caused by syphilis, such as spontaneous abortion, perinatal or infant death, or a living infant with syphilis. Our findings on gonorrhoea during pregnancy are almost as startling. The prevalence of gonorrhoea in pregnant women in many parts of Africa is at least $10 \%$ and it approaches $20 \%$ in some areas. The incidence of gonococcal ophthalmia neonatorum in neonates appears to be between $2 \%$ and $4 \%$. We recommend commitment of health resources to initiatives to prevent and control sexually transmitted disease in Africa and additional research into the cost effectiveness of different prevention and control approaches.

Public health professionals are increasingly recognising the major part that sexually transmitted diseases (STD) play in reproductive health; this recognition has added a new importance to preventing genital infections. The dimensions of the worldwide STD epidemic, and its reproductive sequelae, demand a greater commitment to its prevention and control. Particularly compelling is the need to control fetal wastage, prematurity, and complications in neonates caused by STD, especially in developing countries.

Although the acquired immune deficiency syndrome (AIDS), human papillomavirus infection, and other newly identified STD are attracting much attention, we must remain vigilant to the serious sequelae of syphilis and gonorrhoea, especially in areas where these traditional "venereal diseases" have not been controlled. The problems currently associated in Africa with syphilis and gonorrhoea during pregnancy are strikingly reminiscent of those faced by the western world in the early 1900s. In this paper, we describe the seriousness and extent of these current

Address for reprints: Dr K F Schulz, US Department of Health and Human Services, Public Health Service, Centers for Disease Control, Center for Prevention Services, Division of Sexually Transmitted Diseases, Atlanta, Georgia 30333, USA.

Accepted for publication 16 November 1986 public health problems in Africa. Firstly, we address syphilis during pregnancy, and, secondly, gonococcal ophthalmia neonatorum (GON), a serious sequel of gonorrhoea during pregnancy. Lastly, we make recommendations for further STD research and for new STD prevention and control initiatives.

\section{Syphilis during pregnancy}

PREVALENCE OF SYPHILIS IN PREGNANT WOMEN Reported prevalences of syphilis seroreactivity in pregnant women attending antenatal clinics in Africa range from $4 \%$ to $15 \%$ (table 1 ). ${ }^{1-10}$ Not only are these findings consistently high across the continent, but they may even be underestimates. For example, in two of the studies treponemal tests yielded much higher prevalences than non-treponemal tests in the same women. ${ }^{59}$ Moreover, in Zambia, researchers analysed the rapid plasma reagin (RPR) test and found a false positive rate of $5 \%$ and a false negative rate of $11 \%$ to $14 \%$, which led them to conclude that the actual prevalence of syphilis may be slightly higher. $^{8}$

One problem with serological tests is that yaws and endemic syphilis can also cause seroreactivity. The countries referred to in table 1, however, are not recognised as African foci of yaws or endemic 
Table 1 Positive reactions to Venereal Disease Research Laboratory and rapid plasma reagin tests in pregnant women in Africa, 1970-85

\begin{tabular}{|c|c|c|}
\hline Country and year & Reference & $\%$ positive \\
\hline \multicolumn{3}{|l|}{ Central African } \\
\hline Republic 1980 & Widy-Wirski and D'Costa ${ }^{3}$ & 10 \\
\hline Ethiopia 1977 & Friedmann and Wright ${ }^{1}$ & 13 \\
\hline Ethiopia 1970 & Larsson and Larsson ${ }^{2}$ & 15 \\
\hline Mozambique 1985 & Liljestrand, et al ${ }^{10}$ & 5 to 15 \\
\hline Rwanda 1982 & De Clercq $^{4}$ & 4 \\
\hline Swaziland 1980 & Meheus, et $a l^{5}$ & 14 \\
\hline Zambia 1980 & Ratnam, et $a l^{6}$ & 15 \\
\hline Zambia 1982 & Ratnam, et al ${ }^{7}$ & 14 \\
\hline Zambia 1984 & Hira $^{8}$ & 13 \\
\hline Zambia 1984 & Watts, et al & 15 \\
\hline
\end{tabular}

syphilis. $^{911}$ Only two of the countries, Central African Republic and Rwanda, reported yaws to WHO in the 1970s, and the numbers of cases were relatively small. ${ }^{11}$ These serological findings therefore probably reflect sexually acquired syphilis rather than non-venereal treponemal infections.

These serological results came primarily from major African cities. Though they may not be representative of the entire continent, the published results are remarkably consistent, and unpublished reports from other countries in Africa, moreover, yield results that often exceed $10 \%$. Syphilis therefore appears to be highly prevalent in many areas of Africa, and is probably not restricted to a few major cities.

\section{EFFECT OF UNTREATED SYPHILIS ON OUTCOME OF PREGNANCY}

The best estimates of the outcome of pregnancies of women with syphilis in Africa that continue to the third trimester come from earlier western data, which present African conditions appear to simulate. One study was published in 1917 in the era before effective syphilis treatment was available (table 2), ${ }^{12}$ and the other was published in 1951 in the era before modern syphilis control programmes were operational (table 3). ${ }^{13}$ These two prominent studies both reported that about one third of pregnancies yielded a non-infected infant. The agreement between the two studies is remarkable, given both the disparity in time and the differences in study populations. The older study resulted in a higher percentage of deaths and a lower percentage of infected infants, presumably because an appreciable percentage of the infected infants died during their first year of life; the more recent study only measured death during the neonatal period. Treatment of neonates in $\mathbf{1 9 5 0}$ was also more effective because of the availability of modern antibiotics. In addition, some women thought to have untreated latent syphilis may already have received penicillin, as it was available during the late 1940s.

When untreated, early and late syphilis apparently
Table 2 Effect of untreated syphilis on outcome of pregnancy in England, $1917^{12}$

\begin{tabular}{ll}
\hline Outcome of pregnancy & $\%$ \\
\hline Stillbirth or late miscarriage & 17 \\
Infant death & 23 \\
Infected infant & 21 \\
Non-infected infant & 39 \\
\hline
\end{tabular}

produce widely disparate outcomes of pregnancy (table 3). Assumptions regarding the early or late status of syphilis are therefore essential to the accurate estimation of outcome of pregnancy for pregnant women with syphilis. In the study that documented early and late status, $73 \%$ of patients were classified as having early syphilis. ${ }^{13}$ In a recent report from Africa, RPR card test measured results for seroreactive women were analysed: $70 \%$ had a titre of $1 / 8$ or more, which corresponds to that found in early untreated syphilis. ${ }^{9}$ The outcomes from the 1951 study therefore seem to be roughly applicable to Africa, and we have used them as theoretical estimates to be applied to untreated pregnant women with syphilis in Africa.

\section{INCIDENCE OF CONGENITAL SYPHILIS}

Congenital syphilis is an extremely serious condition that is often disfiguring and debilitating, if not fatal. Moreover, its manifestations appear to be much worse in Africa than in the United States of America (Naeye, personal communication). Data on congenital syphilis in Africa are not as abundant as on syphilis in adults during pregnancy, but the data that are available are comprehensive. A study in Zambia established that nearly $1 \%$ of the babies delivered at the University Teaching Hospital in Lusaka had signs of congenital infection at birth, and as many as $6.5 \%$ were seroreactive at birth and thus considered to be at risk. ${ }^{14}$ These data are consistent with prior reports in that most congenital syphilis is not diagnosed until weeks or months after birth. In another study from Zambia, seroreactivity in infants under six months old was $2.9 \%{ }^{8}$ Half the seroreactive infants had two or more clinical features suggestive of early congenital syphilis and, of these, $60 \%$ required admission to hospital. Moreover, the RPR test was used and found by

Table 3 Effect of untreated syphilis on outcome of pregnancy, Philadelphia General Hospital, 1951 13

\begin{tabular}{llll}
\hline \multirow{2}{*}{$\begin{array}{l}\text { Outcome } \\
\text { of pregnancy }\end{array}$} & \multicolumn{2}{l}{$\%$ with: } & \\
\cline { 2 - 3 } & Early syphilis & Late syphilis & Total \\
\hline Stillbirth & 25 & 12 & 22 \\
Neonatal death & 14 & 9 & 12 \\
Infected infant & 41 & 2 & 33 \\
Non-infected infant & 20 & 77 & 33 \\
\hline
\end{tabular}


the Zambian researchers to have a false positive rate of $1 \%$ and a false negative rate of $52 \%$ to $62 \%{ }^{8}$ This suggests that the incidence of congenital syphilis may be much higher than that obtained with the RPR test.

These data are consistent with what is known about the transmission of syphilis from mother to infant. A pregnant mother with untreated syphilis apparently has a $33 \%$ chance of giving birth to a live infant with syphilis (table 3 ). The prevalence of seroreactivity in the pregnant women in the studies from Zambia was $13 \%$ to $15 \%$. Consequently, if syphilis in those women was not treated, we would expect that $33 \%$ of the pregnancies would end in live infants with syphilis-that is, $4 \%$ to $5 \%$ of babies born. The congenital syphilis seroreactivity rates of $2.9 \%$ and $6.5 \%$ are within the expected range, and the higher rate of $6.5 \%$ could, moreover, have been caused by passive antibody transfer at birth.

Further confirmation of the incidence and problems associated with early congenital syphilis in Zambia comes from two treatment studies. Early congenital syphilis was diagnosed in $9 \%$ of admissions in one of the nursery wards ${ }^{15}$ and $8 \%$ of admissions to the intensive care unit. ${ }^{16}$

\section{PERINATAL, NEONATAL, AND INFANT DEATHS}

The relation between syphilis during pregnancy and stillbirths is well established. A recent case control study of the relation between stillbirths and high titre RPR card test seroreactivity in Zambia yielded a relative risk of 28 (95\% confidence interval of 12 to 63$).^{9}$ This result is consistent with the 1951 study from the United States of America, which showed that the relative risk of stillbirths for a mother with untreated early syphilis was 32 times greater than for a noninfected mother. ${ }^{13}$ In pregnant women with untreated early syphilis, nearly $40 \%$ of pregnancies result in perinatal death; in pregnant women with untreated late syphilis over $20 \%$ result in perinatal death (table 3).

In the University Teaching Hospital in Lusaka, Zambia, $42 \%$ of stillbirths were attributed to syphilis during pregnancy. ${ }^{7}$ In Zambia, congenital syphilis was implicated in $20 \%$ to $30 \%$ of the total perinatal infant mortality, which was 50 per 1000 births. ${ }^{8}$ In other words, $1-1 \cdot 5 \%$ of all Zambian pregnancies that extend beyond 20 to 27 weeks end in death caused by syphilis. This is an underestimate, moreover, because it does not include post neonatal infant deaths and because many stillborn infants do not have clinical evidence of congenital syphilis.

In Ethiopia, studies conducted on perinatal mortality identified syphilis as the fourth commonest cause of perinatal death accounting for $10 \%$ of about 70 perinatal deaths per 1000 births. ${ }^{17}$ Studies also found that syphilis causes nearly $5 \%$ of all post neo- natal infant deaths. ${ }^{17}$ Thus, at least $1 \%$ of Ethiopian pregnancies extending beyond 20 to 27 weeks end in perinatal or post neonatal infant death caused by syphilis. In absolute numbers, 15000 fetal and infant deaths each year are directly attributable to syphilis in Ethiopia. ${ }^{18}$

\section{SPONTANEOUS ABORTION}

The largest absolute effect of syphilis during pregnancy is probably spontaneous abortion during the middle trimester and early in the third trimester. Researchers estimate that $5 \%$ of all pregnancies in Ethiopia are lost because of syphilis, a total of 75000 pregnancy losses each year, ${ }^{18}$ whereas in Zambia $19 \%$ of miscarriages were attributed to syphilis. ${ }^{7}$ Pregnant women in Ethiopia who were found to be seropositive to tests for syphilis were five times more likely to have an abortion or stillbirth than women who were seronegative. ${ }^{2}$ These data strongly point to spontaneous abortion being a major adverse outcome of syphilis during pregnancy. The precise magnitude, however, is difficult to measure anywhere in the world, but especially in Africa where women usually do not attend for prenatal care until late in the third trimester.

The estimate from Ethiopia that many pregnancies are lost to spontaneous abortion due to syphilis during pregnancy appears to be plausible. Between $15 \%$ and $43 \%$ of post implantation pregnancies in the Western world are lost to spontaneous abortion. ${ }^{1920}$ Given the nutritional and health status of most African women, we estimate that $45 \%$ of their pregnancies spontaneously abort.

Many spontaneous abortions would not be affected by syphilis, however, as first trimester abortions are usually associated with phenotypic or chromosomal fetal abnormalities. ${ }^{21}$ Considering all available data, syphilis is likely to cause a few spontaneous abortions in the first trimester, but has a very pronounced effect in the middle trimester and early in the third trimester. ${ }^{22}$ Most miscarriages occur in the first trimester so we estimate that two thirds could not be caused by syphilis, which leaves a baseline spontaneous abortion rate of $15 \%$ after the first trimester. The best available data indicate that a woman with untreated early syphilis is $\mathbf{3 . 3}$ times more likely to have a iniscarriage or premature stillbirth than a noninfected woman. ${ }^{13}$ This would appear to be a conservative estimate as stillbirth at full term is associated with a relative risk of about 30 , as noted earlier. In fact, if an infection is acquired from an expectant mother with early syphilis in the second trimester, spontaneous abortion is the most probable outcome. ${ }^{11}$ Thus we would expect the spontaneous abortion rate in pregnant women with untreated syphilis to be 3.3 times $15 \%$, or at least $50 \%$. In conclusion, 
we estimate that of pregnancies that extend beyond 12 weeks gestation, $15 \%$ in non-infected women and $50 \%$ in women with syphilis would spontaneously abort. These estimates are consistent with what we know about spontaneous abortion and the pathogenesis of syphilis during pregnancy.

\section{MODEL OF OUTCOMES OF PREGNANCY IN}

SUB-SAHARAN AFRICA

We assumed an estimated $10 \%$ seroreactivity in pregnant women and followed 1000 women in a model. We used the aforementioned theoretical estimates in a simple deterministic model (table 4) and then compared the results from the model with actual reported data from Africa. The estimate that $5 \%$ of all pregnancies in Ethiopia are lost to spontaneous abortion caused by syphilis during pregnancy appeared to be plausible. The model yielded a consistent estimate of $3.5 \%$. If instead we assumed a $15 \%$ prevalence of seroreactivity, the model would also yield an estimate of about $5 \%$.

Of pregnancies that extend beyond 20 to 27 weeks, the model yielded $1.7 \%$ more perinatal deaths caused by syphilis, which was consistent with, though slightly higher than, the $1 \%$ to $1.5 \%$ estimates from Ethiopia and Zambia. Using the model we also estimated that $20 \%$ of perinatal deaths were caused by syphilis, which was consistent with the $10 \%$ to $30 \%$ reported from Zambia and Ethiopia.

In the model, $2 \cdot 1 \%$ of pregnancies that extended into the perinatal period resulted in infants with syphilis, which was consistent with results from Zambia of $1 \%$ with signs of congenital syphilis at birth and $2.9 \%$ to $6.5 \%$ seroreactive at birth or shortly thereafter.

\section{CONCLUSIONS ON SYPHILIS DURING PREGNANCY} IN AFRICA

Based on the most current studies, prevalence of syphilis seroreactivity in pregnant women in many parts of Africa is at least $10 \%$. Assuming that prevalence: $3 \%$ to $4 \%$ of pregnancies that extend beyond 12 weeks will spontaneously abort because of syphilis; $1-2 \%$ of pregnancies that extend beyond 20 to 27

Table 4 Reproductive outcome model assuming 10\% seroreactivity in 1000 pregnant women

\begin{tabular}{lll}
\hline Outcome & $\begin{array}{l}\text { Seroreactive } \\
(n=100)\end{array}$ & $\begin{array}{l}\text { Non-seroreactive } \\
(n=900)\end{array}$ \\
\hline $\begin{array}{l}\text { Spontaneous abortion in 2nd or } \\
\text { early 3rd trimester }\end{array}$ & $50(50 \%)$ & $135(15 \%)$ \\
$\begin{array}{l}\text { Excess abortions } \\
\text { caused by syphilis }\end{array}$ & 35 & 0 \\
$\begin{array}{l}\text { Pregnancies extending } \\
\text { beyond 20 to 27 weeks }\end{array}$ & 50 & 765 \\
$\begin{array}{l}\text { Perinatal deaths } \\
\text { Excess perinatal deaths }\end{array}$ & $17(34 \%)$ & $54(7 \%)$ \\
Infants with syphilis & 14 & 0 \\
\hline
\end{tabular}

Table 5 Percentage of children blind because of gonococcal ophthalmia neonatorum (GON) and number of states requiring prophylaxis ${ }^{26}$

\begin{tabular}{lll}
\hline $\begin{array}{l}\text { Period } \\
\text { covered }\end{array}$ & $\begin{array}{l}\text { No of states } \\
\text { requiring prophylaxis }\end{array}$ & $\begin{array}{l}\text { Average percentage } \\
\text { blindness caused by GON }\end{array}$ \\
\hline $1906-11$ & 1 & $24 \cdot 1$ \\
$1916-21$ & 23 & $17 \cdot 5$ \\
$1926-31$ & 39 & $8 \cdot 9$ \\
$1936-41$ & 46 & $7 \cdot 4$ \\
$1946-51$ & 47 & $1 \cdot 8$ \\
$1951-56$ & 48 & $0 \cdot 5$ \\
$1958-59$ & 50 & $0 \cdot 3$ \\
\hline
\end{tabular}

weeks will end in perinatal or infant death because of syphilis, and $1-2 \%$ of pregnancies that extend beyond 20 to 27 weeks will yield an infant with syphilis. Assuming a seroreactivity rate of $10 \%$, therefore, an aggregate of $5 \%$ to $8 \%$ of pregnancies surviving past 12 weeks - that is, $50 \%$ to $80 \%$ of those in seropositive women-will have an adverse outcome caused by syphilis.

\section{Gonococcal ophthalmia neonatorum}

\section{SERIOUSNESS OF GONOCOCCAL OPHTHALMIA NEONATORUM}

Gonococcal ophthalmia neonatorum (GON), if untreated, often leads to blindness. The incidence of blindness from GON in Africa is unknown, but historical data from industrialised countries in childhood blindness can provide some insight. At the turn of the last century, an estimated $20 \%$ to $40 \%$ of children in European homes for the blind were there as a result of GON. ${ }^{23}$ Some estimates were even higher. In 1881 a Liverpool eye surgeon (Grossman) wrote that $60-75 \%$ of blindness in any large home was caused by ophthalmia neonatorum. These results came when prophylaxis and treatment for gonococcal ophthalmia neonatorum did not exist, and levels of gonococcal infection in pregnant women were similar to those now present in Africa. The incidence of GON dropped dramatically after Crede introduced prophylactic treatment. ${ }^{24}$ As more states passed laws requiring prophylaxis, the percentage of children in homes whose blindness was caused by GON steadily declined (table 5), ${ }^{25}$ this illustrates a temporal association between prophylaxis and the importance of GON in blindness.

GON is no longer a cause of blindness in industrialised countries because of effective diagnosis and treatment of women during pregnancy or effective prophylaxis of neonates, or both. In developing countries, blindness in children is not reported as being highly prevalent. The World Health Organisation (WHO) concludes that in developing countries, blind children have a high mortality rate, so the true prob- 
lem would not be apparent in prevalence surveys. ${ }^{23} 26$ Moreover, the level of blindness related to GON is unknown. ${ }^{26}$

Extrapolating from conditions in the industrialised world at the turn of the century to present day Africa appears to be reasonable. Conditions prevailing in Africa now regarding gonococcal ophthalmia neonatorum are similar to those in the industrialised world during Crede's time: the prevalence of gonococcal infection in pregnant women in many parts of present day Africa is at a high level (more than $10 \%$ of pregnant women); ocular prophylaxis in Africa is not available, has been discontinued, or is incompletely applied; an increasing number of gonococcal infections $(10-80 \%)$ are caused by penicillinase producing Neisseria gonorrhoeae (PPNG), only limited treatment is available for GON in general, and no or only inadequate treatment is possible for infections caused by PPNG strains.

\section{PREVALENCE OF GONORRHOEA IN PREGNANT} WOMEN IN AFRICA

The prevalence of $N$ gonorrhoeae in pregnant women in Africa is reported as being between 3\% and $22 \%$ (table 6). Many countries, including Cameroon, Kenya, Uganda, and Senegal, have documented rates of $18 \%$ or higher. The studies that yielded these prevalence rates were undertaken in urban settings, and many researchers believe that gonorrhoea is more prevalent in towns than in rural settings. Gonococcal infection, however, may even be more common in some populations of rural women. For example, a study done at Yaounde Central Hospital in the United Republic of Cameroon, an urban setting, yielded a gonorrhoea infection rate of $14 \% .{ }^{28}$ The same authors found that $22 \%$ of rural women had gonorrhoea; this higher prevalence in a rural setting may lead to gonococcal ophthalmia neonatorum being a more serious complication because of less

Table 6 Prevalence of Neisseria gonorrhoeae in pregnant women in Africa

\begin{tabular}{|c|c|c|}
\hline Country & Reference & $\%$ Positive \\
\hline $\begin{array}{l}\text { Cameroon (urban) } \\
\text { Cameroon (rural) } \\
\text { Cameroon } \\
\text { Central African } \\
\text { Republic } \\
\text { Gambia } \\
\text { Ghana } \\
\text { Kenya } \\
\text { Kenya } \\
\text { Nigeria } \\
\text { Senegal } \\
\text { South Africa } \\
\text { Swaziland } \\
\text { Tanzania } \\
\text { Uganda }\end{array}$ & 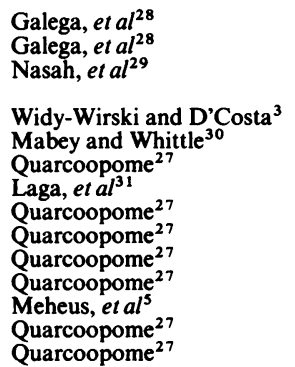 & $\begin{array}{r}10 \\
7 \\
3 \\
7 \\
18 \\
4 \\
19 \\
10 \\
4 \\
8 \\
18\end{array}$ \\
\hline
\end{tabular}

adequate medical care. Obviously, however, more data are needed from the rural areas of sub-Saharan Africa.

\section{INCIDENCE OF GONOCOCCAL OPHTHALMIA NEONATORUM IN NEONATES}

About $30 \%$ of infants exposed to $N$ gonorrhoeae during birth will develop gonococcal eye infections if prophylaxis is not given; this implies that up to $6 \%$ of infants born in Africa will develop gonococcal ophthalmia. ${ }^{23}$ Transmission rates of $42 \%$ to $48 \%$ have been found in Kenya. ${ }^{31} 32$ The best estimates of the incidence of gonococcal ophthalmia neonatorum place the rates between $0.5 \%$ to $5 \% .^{23}$ These estimates look reasonable and are corroborated by available data from both east and west Africa. In Cameroon, $4 \%$ of neonates had GON. ${ }^{28}$ Corresponding rates from large hospitals in Kenya were $3.6 \%$ and in Ethiopia were $6 \cdot 3 \% .3233$ These incidence rates were over 50 times higher than the rates from the western world, which averaged $0.06 \% .^{34}$

Not only are the GON rates high in Africa, but many cases may not be diagnosed because of inaccessibility to the health care system or lack of symptoms of disease. Moreover, only limited treatment is usually available for GON in general, with no treatment or only inadequate treatment possible for PPNG infections. Huge numbers of children are thus exposed to the risk of blindness and potentially, as a consequence, death.

\section{CONCLUSIONS ON CONOCOCCAL OPHTHALMIA NEONATORUM IN AFRICA}

Based on the most current studies, the prevalence of gonorrhoea in pregnant women in many parts of Africa is at least $10 \%$ and it approaches $20 \%$ in some areas. The incidence of GON in neonates in Africa ranges between $0.5 \%$ and $6 \%$, and incidences of $2 \%$ to $4 \%$ are common.

\section{Recommendations}

SYPHILIS DURING PREGNANCY

Based on available research, which documents the seriousness and extent of the problems caused by syphilis during pregnancy, funds must be committed to Africa for the prevention and control of syphilis. Research must be conducted into the most cost effective approaches to prevent and control the serious sequelae of syphilis during pregnancy, including contact tracing and treatment procedures in an African setting. Further research on the prevalence of syphilis during pregnancy should be initiated, especially in rural areas and in countries where prevalence studies have not been undertaken. 


\section{GONOCOCCAL OPHTHALMIA NEONATORUM}

Based on available research, which documents the seriousness and extent of GON, funds must be committed to Africa for prevention and control initiatives to reduce gonococcal ophthalmia neonatorum. Research must be carried out into the most cost effective approaches for GON prophylaxis, into the most effective GON prophylaxis in various African settings, especially those with high PPNG prevalence, and into the prevalence of gonorrhoea during pregnancy and GON, especially in rural areas and in countries where prevalence studies have not been undertaken.

\section{References}

1 Friedmann PS, Wright DJM. Observations on syphilis in Addis Ababa. 2. Prevalence and natural history. British Journal of Venereal Diseases 1977;53:276-80.

2 Larsson Y, Larsson V. Congenital syphilis in Addis Ababa. Ethiop Med J 1970;8:163-72.

3 Widy-Wirski R, D'Costa J. Maladies transmises par voie sexuelle dans une population rurale en Centrafrique. In: Rapport final, $13^{\mathrm{e}}$ conference technique. Yaounde, Cameroon: OCEAC, 1980:651-4.

4 De Clercq A. Problemes en obstetrique et gynecologie. In: Meheus A, Butera S, Eylenbosch W, Gatera G, Kivits M, Musafili I, eds. Santé et maladies au Rwanda. Bruxelles: Adminstration Générale de la Cooperation au Developpement, 1982:627-56.

5 Meheus A, Freidman F, Van Dyck F, Gruyver T. Genital infections in prenatal and family planning attendants in Swaziland. East Afr Med J 1980;57:212-7.

6 Ratnam AV, Din SN, Chatterjee TK. Sexually transmitted diseases in pregnant women. Med J Zambia 1980;14:75-8.

7 Ratnam AV, Din SN, Hira SK, et al. Syphilis in pregnant women in Zambia. British Journal of Venereal Diseases 1982;58:355-8.

8 Hira SK. Epidemiology of maternal and congenital syphilis in Lusaka and Copperbelt Provinces of Zambia. Lusaka, Zambia: Republic of Zambia, 1984:1-40.

9 Watts TE, Larsen SA, Brown ST. A case-control study of stillbirths at a teaching hospital in Zambia, 1979-80: serological investigations for selected infectious agents. Bull WHO 1984;62:803-8.

10 Liljestrand J, Bergstrom S, Nieuwenhuis F, Hederstedt B. Syphilis in pregnant women in Mozambique. Genitourin Med 1985;61:355-8.

11 World Health Organisation Scientific Group. Treponemal infections. WHO Tech Rep Ser 1982;674:14-8.

12 Harman N. Staying the plague. London: Methuen, 1917. Cited by Murphy FK, Patamasucon P. Congenital syphilis. In: Holmes KK, Mårdh P-A, Sparling PF, Wiesner PJ, eds. Sexually transmitted diseases. New York: McGraw Hill 1984:352-74.

13 Ingraham NR. The value of penicillin alone in the prevention and treatment of congenital syphilis. Acta Derm Venereol (Stockh) 1951;31 suppl 24:60-88.

14 Hira SK, Bhat GJ, Ratnam AV, Chintu C, Mulenga RC. Congenital syphilis in Lusaka. II. Incidence at birth and potential risk among hospital delivered infants. East Afr Med $J$ 1982;59:306-10.

15 Hira SK, Ratnam AV, Sehgal DB, Bhat GJ, Chintu C. Congenital syphilis in Lusaka. I. Incidence in a general nursery ward. East Afr Med J 1982;59:241-6.

16 Bhat GJ, Hira SK, Ratnam AV, Chintu C, Mulenga RC, Congenital syphilis in Lusaka. III. Incidence in neonatal intensive care unit. East Afr Med J 1982;59:374-8.

17 Naeye RL, Tafari N, Marboe CC, Judge DM. Causes of perinatal mortality in an African City. Bull WHO 1977;55:63-5.

18 Bishaw T, Tafari N, Zewdie M, Haile D, Mascola L, Brown S. Prevention of congenital syphilis. In: Nsanze H, Widy-Wirski RH, Ellison RH, eds. Proceedings of the third African regional conference on sexually transmitted diseases. Basle, Switzerland: Ciba Geigy, 1983:148-53.

19 Biggers JD. In vitro fertilization and embryo transfer in human beings. $N$ Engl J Med 1981;304:336-42.

20 Miller JF, Williamson E, Glue J, Gordon YB, Grudzinskas JG, Sykes A. Fetal loss following implantation: a prospective study. Lancet 1980;i:554-6.

21 Poland BJ, Carr DH. Abortion: pathogenesis, cytogenetics. In: Chance GW, ed. Perinatal medicine: the basic science underlying clinical practice. Baltimore: Williams and Wilkins, 1976:48-56.

22 Brunham RC, Holmes KK, Eschenbach D. Sexually transmitted diseases in pregnancy. In: Holmes KK, Mårdh P-A, Sparling PF, Wiesner PJ, eds. Sexually transmitted diseases. New York: McGraw Hill, 1984:782-816.

23 World Health Organisation. Prevention and treatment of conjunctivitis in the newborn at the primary level. Geneva, Switzerland: WHO, 1984:WHO/PBL/84.4;1-23.

24 Crede CSF. Die Verkutung der Augentzundung der Neugeborenen. Archiv für Gynakologie 1881;17:50-3, 18:367-70, 1883;21:179-95.

25 Barsam PC. Specific prophylaxis of gonococcal ophthalmia neonatorum: a review. $N$ Engl $J$ Med 1966;274:731-4.

26 Fransen L, Nsanze H, Klauss V, et al. Ophthalmia neonatorum in Nairobi, Kenya: the roles of Neisseria gonorrhoeae and Chlamydia trachomatis. J Infect Dis 1986;153:862-9.

27 Quarcoopome CO. Ophthalmia neonatorum: problems of prophylaxis and treatment in Africa. Geneva, Switzerland: World Health Organisation, 1983:PBL/ON/83·1, 1-4.

28 Galega FP, Heymann DL, Nasah BT. Gonococcal ophthalmia neonatorum: the case for prophylaxis in tropical Africa. Bull WHO 1984;62:95-8.

29 Nasah BT, Nguematcha R, Eyong M, Godwin S. Gonorrhea, trichomonas and candida among gravid and nongravid women in Cameroon. Int J Gynaecol Obstet 1980;18:48-52.

30 Mabey DCW, Whittle HC. Genital and neonatal chlamydial infection in a trachoma endemic area. Lancet 1982;ii:301-2.

31 Laga M, Nsanze H, Plummer FA, Ndinya-Achola JO, Brunham RC, Piot P. Comparison of tetracycline and silver nitrate for the prophylaxis of chlamydial and gonococcal ophthalmia neonatorum. In: Oriel D, Ridgeway G, Schachter J, TaylorRobinson D, Ward M, eds. Chlamydial infections. Cambridge, England: Cambridge University Press, 1986:301-4.

32 Laga M, Plummer FA, Nzanze H, et al. Epidemiology of ophthalmia neonatorum in Kenya. Lancet 1986;ii:1145-9.

33 Muhe $\mathrm{L}$, Tafari $\mathrm{N}$. Is there a critical time for prophylaxis against neonatal gonococcal ophthalmia? Genitourin Med 1986;62: 356-7.

34 Rothenberg R. Ophthalmia neonatorum due to Neisseria gonorrhoeae: prevention and treatment. Sex Transm Dis 1979;6:187-91. 